\title{
Effects of biopolishing on the quality of cotton fabrics using acid and neutral cellulases

\author{
Mohammad Gias Uddin
}

\begin{abstract}
The aims of the study were to analyze the treatment conditions for the use of acid and neutral cellulase enzymes and evaluate the changes in the various properties of the treated fabrics. In this study, biopolishing was carried out on bleached fabric using acid cellulase (Mega PK) and neutral cellulase (Mega L-1009D) considering three factors: concentration $\left(0.5,1\right.$, and $1.5 \%$ ), temperature $\left(45,55\right.$, and $\left.65^{\circ} \mathrm{C}\right)$, and time $(40,50$, and $60 \mathrm{~min})$. Changes in the physical properties such as weight loss, strength loss, pilling resistance, abrasion resistance (mass loss), and bending length of the biopolished fabrics were measured. Using Mega PK, weight loss and strength loss were found within 0.25 to $1.42 \%$ and 1.7 to $24.7 \%$, respectively, while these values were found within 0.20 to $1.22 \%$ and 1.5 to $18.9 \%$, respectively, using Mega L. On the other hand, pilling and abrasion resistance of the fabrics were improved due to biopolishing. In addition, bending length was found maximum $31.62 \%$ lower than the untreated bleached fabric using Mega PK and 44.26 \% lower using Mega L. It was also concluded that 1 \% Mega PK showed better results when applied at $55{ }^{\circ} \mathrm{C}$ for 40 min, whereas $1 \%$ Mega $L$ showed better results when applied at $55^{\circ} \mathrm{C}$ for 50 min among all the treatment conditions.
\end{abstract}

\section{Background}

Enzymes are a sustainable alternative to the harsh toxic chemicals in the textile industry (Mojsov 2014a). There is a wide range of applications and a multitude of prospects for the use of enzymes in textile processing, leading to a positive impact on the environment (Mojsov 2014b) as enzymes are readily biodegradable (Doshi and Shelke 2001). Cellulase is the most popular and versatile enzyme used in textile wet processing for biopreparation, biopolishing, and softening of cellulosic fibers (Hebeish et al. 2013; El-Sayed et al. 2010). The surface modification of these fibers to improve their outlook by removing superficial fibrils and micro fibrils conferring cooler and softer feel, brighter luminosity of colors, and more resistance to pilling propensity using cellulases is known as biopolishing (Choudhury 2006; Shah 2014; Steward 2005; Ulson de Souza et al. 2013). This is a biological process (Mojsov 2014a; Mojsov 2014b) which employs the same cellulase action on the surface of the cellulosic materials. The process can be carried out at any stage of wet processing but most conveniently performed

Correspondence: giasdtt@gmail.com

Department of Textile Engineering, Faculty of Engineering, Ahsanullah University of Science and Technology, Tejgaon I/A, Dhaka 1208, Bangladesh after bleaching. In addition, this is a permanent process (Shah 2014) and it keeps the fabric in good condition after repeated washing; consequently, products become more attractive to the customer and fetch better prices.

Though the effects of cellulase hydrolysis remain as the surface phenomena, changes in many physical aspects as well as mechanical properties of fabrics take place during the processing. Improvement in the handle value is obtained on account of the changes that take place during the reaction. An important aspect of cellulase for textile application is their relatively slow kinetics which allows the modification of cellulosic fibers in a controlled manner without excessive damage (Andreaus et al. 2104). However, cellulase action should be restricted to the hydrolysis of the loose fibrils created at the surface of the fibers (Morgado et al. 2000), but steam, heat, or alkali pre-treatment can facilitate cellulase penetration to the interior of the fibers and result in more severe hydrolysis (Schimper et al. 2004; Schimper et al. 2009).

Again, the removal of surface fibers or fibrils and an increase in the pilling resistance value are directly related 
to an increase in weight loss, which should not exceed 3-5 \% (Rau et al. 2008). In addition, for knitted fabric, a weight loss of about 1-2\% is reported to be enough to release a remarkable reduction in pilling tendency (Saravanan et al. 2009). On the other hand, commercially, a strength loss of $10 \%$ is considered acceptable due to biopolishing (Choudhury 2006). High enzyme loads and long treatment times may lead to severe fiber damage and strength loss (Andreaus et al. 2104).

The cellulase-catalyzed hydrolysis of cellulose is strongly influenced by factors such as $\mathrm{pH}$, temperature, time, and agitation (Schindler and Hauser 2004). The optimal $\mathrm{pH}$ for a particular cellulase depends upon its origin (Schindler and Hauser 2004). Commercial cellulases for biopolishing originate from Trichoderma reesei and Humicola insolens (Azevedo et al. 2000; Heikinheimo et al. 2000). Acid cellulases are Trichodermabased products which work best at $\mathrm{pH} 4.5-5.5$ at a temperature of $45-55{ }^{\circ} \mathrm{C}$ (Shah 2014; Choudhury 2006). Neutral cellulases from Humicola are more effective at $\mathrm{pH}$ 6.0-7.0 and in the temperature range of $40-55{ }^{\circ} \mathrm{C}$ (Mojsov 2014a; Choudhury 2006).

The careful control of process variables such as concentration, treatment time, and temperature in an enzymatic treatment is important for analyzing the cellulase activity for the enhancement of the product. Therefore, in the present study, an attempt has been made to analyze the treatment conditions for the use of acid and neutral cellulase enzymes and evaluate the changes in properties like weight, strength, abrasion resistance, pilling resistance, and bending length of the treated fabrics.

\section{Methods}

\section{Materials}

The cotton knitted fabric (single jersey) of $160 \mathrm{~g} / \mathrm{m}^{2}$ (yarn count 30/1 Ne) collected from Microfiber Group Limited, Narayangonj, was used throughout the research work. Acid-stable cellulase Mega PK (ECU/mL: 7000) and neutral-stable cellulase Mega L-1009D (ECU/mL: 5000) were procured from Sumcon Biotechnology, Mega Pacific Technology Inc., USA. Sodium hydroxide, sodium carbonate and Glauber's salt (Merck Specialties Private Limited), wetting agent (Primawet, DW conc.), sequestering agent (Primaquest $\mathrm{M}$ conc.), peroxide stabilizer, hydrogen peroxide (35\%), detergent (Primowash), and acetic acid used for the experimental work were laboratory-grade reagents.

\section{Combined scouring-bleaching}

The fabric samples were treated with a solution containing $2.5 \mathrm{~g} / \mathrm{L}$ sodium hydroxide, $1 \mathrm{~g} / \mathrm{L}$ Primaquest $\mathrm{M}$ conc., 1 g/L Primawet DW conc., and 1 g/L Primowash maintaining a liquor ratio of $1: 40$, at $\mathrm{pH} 10.5-11$ and temperature rises up to $45{ }^{\circ} \mathrm{C}$. Then, $35 \%$ hydrogen peroxide $(2.5 \mathrm{~mL} / \mathrm{L})$ and stabilizer $\left(1 / 3\right.$ of $\left.\mathrm{H}_{2} \mathrm{O}_{2}\right)$ were added. The combined process was continued for $45 \mathrm{~min}$ at a temperature of $95{ }^{\circ} \mathrm{C}$. Fabric samples were washed thoroughly and neutralized with $1 \mathrm{~g} / \mathrm{L}$ acetic acid. Finally, the samples were washed with $1 \mathrm{~g} / \mathrm{L}$ Primowash at $80{ }^{\circ} \mathrm{C}$ for $10 \mathrm{~min}$.

\section{Biopolishing}

Mega PK and Mega L enzymes were used to study the effect of biopolishing on cotton fabrics. Sample size, approximately $35 \mathrm{~cm} \times 35 \mathrm{~cm}$, was introduced in the machine pots containing the cellulase in the appropriate buffer system and machine rpm used was 40. Three levels of cellulase concentrations $(0.5,1$, and $1.5 \%)$, temperatures $\left(45,55\right.$, and $\left.65{ }^{\circ} \mathrm{C}\right)$, and treatment duration $(40,50$, and $60 \mathrm{~min}$ ) were used maintaining a material to liquor ratio of 1:10. Mechanical agitation was enhanced by addition of ten steel balls (each weighing $1.04 \mathrm{~g}$ ). For acid and neutral cellulases, bath $\mathrm{pH}$ was maintained at 4.5-5.5 and 7, respectively. Finally, the biopolishing process was terminated by hot treatment at $85{ }^{\circ} \mathrm{C}$ for 10 min. Opticid PSD (1.5 g/L) was used as a buffering agent during Mega PK treatment.

\section{Weight loss}

Loss in weight of biopolished fabrics was measured using Eq. 1:

Weight loss $\%=\frac{\text { (Fabric weight before biopolishing-Fabric weight after biopolishing) }}{\text { Fabric weight before biopolishing }} \times 100$

\section{Strength loss}

The bursting strength of bleached and biopolished fabrics was determined using a bursting strength tester according to ISO 13938-1:1999. The strength loss of the biopolished samples was measured using Eq. 2:

Strenght loss $\%=\frac{(\text { Fabric strength before biopolishing-Fabric strength after biopolishing })}{\text { Fabric strength before biopolishing }} \times 100$

\section{Pilling resistance}

Pilling resistance of the fabrics was determined using Martindale abrasion and a pilling tester $(125,500$, and 2000 rubbing cycles) according to SN 198525:1990. The observed resistance to pilling was reported using a rating scale, showing a range pilling resistance from 1 (very severe pilling) to 5 (no pilling). 


\section{Abrasion (mass loss)}

Mass loss of the fabrics was determined using Martindale abrasion and a pilling tester (100, 250, 500, 750, and 1000 cycles) according to ISO 12947-3:1998.

\section{Bending length}

The bending length of the fabrics was determined using a Shirley stiffness tester according to BS 3356:1990. A rectangular strip of fabric (6 in. $\times 1$ in.) was mounted on a horizontal platform in such a way that it overhung like a cantilever and bends downwards. Then, the bending length was measured from the scale mark opposite a zero line engraved on the side of the platform. Each fabric was tested four times at head and tail ends of face and back sides in a wale direction, and their average was taken.

\section{Results and discussion Weight loss $\%$}

The weight loss of acid- and neutral-stable cellulasetreated cotton fabrics is shown in Table 1.

When $0.5 \%$ Mega PK was applied on the bleached fabric for 40 and $60 \mathrm{~min}$, weight loss was increased gradually with the increase of treatment temperatures as shown in Table 1. As for example, in the case of 40-min time of treatment, weight loss was found to be $0.25 \%$ at $45{ }^{\circ} \mathrm{C}$ while it was increased to 0.27 and $0.29 \%$ for the increase of temperature to 55 and $65{ }^{\circ} \mathrm{C}$, respectively. But for $0.5 \%$ PK application for $50 \mathrm{~min}$, the trend was different. For sample no. 6, weight loss was found to be $0.29 \%$ after biopolishing treatment at $65{ }^{\circ} \mathrm{C}$ which was less than $0.31 \%$ weight loss after the treatment at $55{ }^{\circ} \mathrm{C}$. Again, except sample no. 14, when $1 \%$ PK was applied on fabric for the corresponding time, a similar trend of increasing weight loss with the increase of temperature was found. In addition, in the case of $1.5 \% \mathrm{PK}$ application, in all cases from sample nos. 19 to 27, a similar trend was found. Finally, maximum weight loss was found to be $1.42 \%$ for sample no. 27 when $1.5 \%$ PK was applied for $60 \mathrm{~min}$ at $65^{\circ} \mathrm{C}$.

Furthermore, weight loss was found increased with the increase of concentration of Mega PK. Using $0.5 \% \mathrm{PK}$, weight loss was found within 0.25 to $0.39 \%$, while using 1 and $1.5 \% \mathrm{PK}$, the losses were found within 0.62 to $0.89 \%$ and 0.98 to $1.42 \%$, respectively. In addition, it can be said that weight loss was found increased with the increase of treatment time (except sample no. 6). In case of sample no. 6 , a weight loss of $0.29 \%$ was found when treating the fabric with $0.5 \% \mathrm{PK}$ at $65{ }^{\circ} \mathrm{C}$ for $50 \mathrm{~min}$, which was also found in case of the $40-\mathrm{min}$ treatment under similar conditions.

From Table 1, for neutral cellulase (Mega L), it was clearly found that with the increase of concentration,
Table 1 Weight loss of Mega-PK- and Mega-L-treated cotton

\begin{tabular}{|c|c|c|c|c|c|}
\hline \multirow{2}{*}{$\begin{array}{l}\text { Sample } \\
\text { no. }\end{array}$} & \multirow{2}{*}{$\begin{array}{l}\text { Concentration } \\
(\%)\end{array}$} & \multirow{2}{*}{$\begin{array}{l}\text { Temperature } \\
\left({ }^{\circ} \mathrm{C}\right)\end{array}$} & \multirow{2}{*}{$\begin{array}{l}\text { Time } \\
(\mathrm{min})\end{array}$} & \multicolumn{2}{|c|}{ Weight loss (\%) } \\
\hline & & & & Mega PK & Mega L \\
\hline 1 & 0.5 & 45 & 40 & 0.25 & 0.2 \\
\hline 2 & 0.5 & 55 & 40 & 0.27 & 0.24 \\
\hline 3 & 0.5 & 65 & 40 & 0.29 & 0.27 \\
\hline 4 & 0.5 & 45 & 50 & 0.26 & 0.31 \\
\hline 5 & 0.5 & 55 & 50 & 0.31 & 0.35 \\
\hline 6 & 0.5 & 65 & 50 & 0.29 & 0.38 \\
\hline 7 & 0.5 & 45 & 60 & 0.33 & 0.42 \\
\hline 8 & 0.5 & 55 & 60 & 0.35 & 0.45 \\
\hline 9 & 0.5 & 65 & 60 & 0.39 & 0.49 \\
\hline 10 & 1 & 45 & 40 & 0.62 & 0.61 \\
\hline 11 & 1 & 55 & 40 & 0.65 & 0.66 \\
\hline 12 & 1 & 65 & 40 & 0.69 & 0.71 \\
\hline 13 & 1 & 45 & 50 & 0.72 & 0.74 \\
\hline 14 & 1 & 55 & 50 & 0.70 & 0.79 \\
\hline 15 & 1 & 65 & 50 & 0.76 & 0.82 \\
\hline 16 & 1 & 45 & 60 & 0.82 & 0.84 \\
\hline 17 & 1 & 55 & 60 & 0.86 & 0.86 \\
\hline 18 & 1 & 65 & 60 & 0.89 & 0.88 \\
\hline 19 & 1.5 & 45 & 40 & 0.98 & 0.95 \\
\hline 20 & 1.5 & 55 & 40 & 1.05 & 0.97 \\
\hline 21 & 1.5 & 65 & 40 & 1.12 & 0.99 \\
\hline 22 & 1.5 & 45 & 50 & 1.17 & 1.02 \\
\hline 23 & 1.5 & 55 & 50 & 1.21 & 1.06 \\
\hline 24 & 1.5 & 65 & 50 & 1.26 & 1.09 \\
\hline 25 & 1.5 & 45 & 60 & 1.32 & 1.13 \\
\hline 26 & 1.5 & 55 & 60 & 1.36 & 1.17 \\
\hline 27 & 1.5 & 65 & 60 & 1.42 & 1.22 \\
\hline
\end{tabular}

time, and temperature, weight loss \% was increased in the case of all the biopolished samples. Maximum weight loss was found to be $1.22 \%$ in the case of $1.5 \%$ Mega L application on fabric for $60 \mathrm{~min}$ at $65{ }^{\circ} \mathrm{C}$ (sample no. 27), while minimum loss was found to be 0.2 for $0.5 \%$ concentration of this enzyme application at $45{ }^{\circ} \mathrm{C}$ for 40 min (sample no. 1).

In general, it can be said that due to the increase of concentration, time, and temperature of cellulase application, the removal of protruding fibers from the surface of the fabric increased, and consequently under such condition, weight loss was increased and vice versa.

Mechanical agitation during the cellulase treatment in the initial stage helps cellulase adsorption and desorption processes. The removal of enzymatically loosened material from fiber surfaces leaves the fibers 
very clean and smooth. Due to this polishing effect, some weight loss was observed, which however did not indicate major fiber damage.

Finally, when weight loss of Mega-PK-treated samples was compared to that of Mega-L-treated samples, it was observed that the weight loss\% of PK-treated samples was slightly higher in the case of sample nos. 1,2 , and 3 under lower concentration of cellulases $(0.5 \%)$. But with the increase of treatment time, weight loss decreased in the case of PK-treated samples as shown in samples 4 to 9 . In samples 11 to 16 , with the treatment of $1 \%$ cellulases, weight loss\% was slightly lower in PK-treated samples. In contrast, in the case of higher concentration $(1.5 \%)$ of cellulase application, weight loss was greater in all PK-treated samples than the Mega-L-treated samples (samples 19 to 27). It indicated that Mega PK was more active in action compared to Mega $\mathrm{L}$ as there is less chance of cellulose degradation in the neutral condition compared to the acidic condition.

\section{Bursting strength loss}

Bursting strength loss\% of acid- and neutral-stable enzyme-treated samples is shown in Table 2.

When $0.5 \%$ Mega PK was used for biopolishing of the bleached fabric, strength loss was found within 1.7 to $7.4 \%$ under different treatment times and temperatures. In addition, strength loss was found increased with the increase of concentration of PK. As for example, when $1 \%$ PK was used, strength loss was found within 8.2 to $15.6 \%$, and in the case of $1.5 \%$ PK application, the loss was within 16.5 to $24.7 \%$. It was obvious in this study that the concentration of cellulase is the most important factor in influencing the strength loss.

Treatment time has also an important effect on strength loss apart from the cellulase concentration. When $0.5 \%$ Mega PK was used for $40 \mathrm{~min}$ at $45{ }^{\circ} \mathrm{C}$, strength loss was $1.7 \%$, while it was found to be $4.9 \%$ only with the increase of time from 40 to $50 \mathrm{~min}$ and $5.8 \%$ with the increase of time from 50 to $60 \mathrm{~min}$ at $45{ }^{\circ} \mathrm{C}$. Similarly, for $1 \%$ PK application at $45{ }^{\circ} \mathrm{C}$, strength loss was $8.2 \%$ for $40 \mathrm{~min}$ time of treatment, and this further increased to 11.5 and $14 \%$ for time 50 and $60 \mathrm{~min}$, respectively. In addition, when $1.5 \%$ PK was applied at $45{ }^{\circ} \mathrm{C}$ for $40 \mathrm{~min}$, strength loss was found to be $16.5 \%$ and strength loss increased to 18.9 and $23.1 \%$ for time 50 and $60 \mathrm{~min}$, respectively.

But in comparison to concentration and time factor, selected temperatures within $45-65{ }^{\circ} \mathrm{C}$ did not play so much influential effect on strength loss. As for example, for $0.5 \%$ PK application for $50 \mathrm{~min}$, strength loss was $4.9 \%$ at $45{ }^{\circ} \mathrm{C}$; at $55{ }^{\circ} \mathrm{C}$, it was $5 \%$ and at $65{ }^{\circ} \mathrm{C} 5.8 \%$. Again, for $1 \%$ PK applied for $60 \mathrm{~min}$ at 45,55 , and $65{ }^{\circ} \mathrm{C}$ temperatures, the strength losses were $14,14.8$, and $15.6 \%$,
Table 2 Bursting strength loss of Mega-PK- and Mega-L-treated fabrics

\begin{tabular}{|c|c|c|c|c|c|}
\hline \multirow{2}{*}{$\begin{array}{l}\text { Sample } \\
\text { no. }\end{array}$} & \multirow{2}{*}{$\begin{array}{l}\text { Concentration } \\
(\%)\end{array}$} & \multirow{2}{*}{$\begin{array}{l}\text { Temperature } \\
\left({ }^{\circ} \mathrm{C}\right)\end{array}$} & \multirow{2}{*}{$\begin{array}{l}\text { Time } \\
(\mathrm{min})\end{array}$} & \multicolumn{2}{|c|}{ Strength loss (\%) } \\
\hline & & & & Mega PK & $\overline{\text { Mega L }}$ \\
\hline 1 & 0.5 & 45 & 40 & 1.7 & 1.5 \\
\hline 2 & 0.5 & 55 & 40 & 2.5 & 2.2 \\
\hline 3 & 0.5 & 65 & 40 & 4.1 & 3 \\
\hline 4 & 0.5 & 45 & 50 & 4.9 & 3.2 \\
\hline 5 & 0.5 & 55 & 50 & 5 & 3.3 \\
\hline 6 & 0.5 & 65 & 50 & 5.8 & 4.1 \\
\hline 7 & 0.5 & 45 & 60 & 5.8 & 4.9 \\
\hline 8 & 0.5 & 55 & 60 & 6.6 & 5.8 \\
\hline 9 & 0.5 & 65 & 60 & 7.4 & 5.9 \\
\hline 10 & 1 & 45 & 40 & 8.2 & 6.6 \\
\hline 11 & 1 & 55 & 40 & 9 & 7.4 \\
\hline 12 & 1 & 65 & 40 & 10.7 & 8.2 \\
\hline 13 & 1 & 45 & 50 & 11.5 & 9.1 \\
\hline 14 & 1 & 55 & 50 & 12.4 & 9.9 \\
\hline 15 & 1 & 65 & 50 & 13.2 & 10.7 \\
\hline 16 & 1 & 45 & 60 & 14 & 11.5 \\
\hline 17 & 1 & 55 & 60 & 14.8 & 11.6 \\
\hline 18 & 1 & 65 & 60 & 15.6 & 12.4 \\
\hline 19 & 1.5 & 45 & 40 & 16.5 & 12.5 \\
\hline 20 & 1.5 & 55 & 40 & 17.3 & 13.2 \\
\hline 21 & 1.5 & 65 & 40 & 18.1 & 14 \\
\hline 22 & 1.5 & 45 & 50 & 18.9 & 14.8 \\
\hline 23 & 1.5 & 55 & 50 & 20.6 & 15.6 \\
\hline 24 & 1.5 & 65 & 50 & 22.2 & 16.5 \\
\hline 25 & 1.5 & 45 & 60 & 23.1 & 17.3 \\
\hline 26 & 1.5 & 55 & 60 & 23.9 & 18.1 \\
\hline 27 & 1.5 & 65 & 60 & 24.7 & 18.9 \\
\hline
\end{tabular}

respectively, and for $1.5 \%$ PK applied for $60 \mathrm{~min}$ at 45, 55, and $65{ }^{\circ} \mathrm{C}$ temperatures, the strength losses were 23.1, 23.9 , and $24.7 \%$.

On the other hand, in the case of neutral-stable enzyme-treated samples, when $0.5 \%$ Mega L was applied, strength loss was found within 1.5 to $5.9 \%$ under different treatment temperatures and times. With the increase of concentration from 0.5 to $1 \%$, strength loss was increased and found within 6.6 to $12.4 \%$, and a further strength loss of 12.5 to $18.9 \%$ was found using $1.5 \%$ Mega L under three different temperatures and three different time combinations.

Again, for neutral cellulase enzyme, treatment time played more impact on strength loss than the treatment temperature. As for example, when $0.5 \%$ Mega L was applied for $40 \mathrm{~min}$, the strength losses were found to be 
$1.5,2.2$, and $3 \%$, respectively, at 45,55 , and $65{ }^{\circ} \mathrm{C}$ temperatures. But for $0.5 \%$ Mega L application at $45{ }^{\circ} \mathrm{C}$ for $50 \mathrm{~min}$, the strength loss increased to $3.2 \%$, at $55{ }^{\circ} \mathrm{C}$ for $50 \mathrm{~min}$ to $3.3 \%$, and at $65{ }^{\circ} \mathrm{C}$ for $50 \mathrm{~min}$ finally to $4.1 \%$.

For $1.5 \%$ Mega L application to bleached fabrics at $55{ }^{\circ} \mathrm{C}$ temperature, strength losses were found to be $13.2,15.6$, and $18.1 \%$, respectively, for 40-, 50-, and 60-min treatment times, whereas when the temperature decreased to $45{ }^{\circ} \mathrm{C}$ for $40 \mathrm{~min}$, strength loss decreased to $12.5 \%$, and when it increased to $65{ }^{\circ} \mathrm{C}$ for $40 \mathrm{~min}$, strength loss increased to $14 \%$. In general, cotton fabric exhibited a loss in bursting strength due to the biodegradation of cellulose by the cellulase.

In this study, concentration had a maximum effect on strength loss followed by treatment time of 40 to $60 \mathrm{~min}$. But prolonged treatment time exceeding 60 min may have significant impact on strength loss, as degradation can occur in the accessible amorphous areas of large pores and at crystalline surfaces.

The findings of strength loss found in the study indicated that the presence of increased amounts of cellulase enzyme in the biotreatment medium causes progressive interactions in a key and lock fashion between the enzyme and cotton cellulose of the fabric. In doing so, cellulose chains undergo molecular scission at $1,4 \beta$-glucosidic linkages, thereby reducing the degree of polymerization of cotton. This, together with the loosening of the fabric structure by virtue of its loss in fabric weight, would account for the decrease in fabric strength. Moreover, biodegradation of fibers along the spiral plane of cellulose might have contributed to the initial strength loss, and when the fissures reached the lumen, further degradation in strength might have occurred rapidly.

From Table 2, it was crystal clear that more strength loss occurred in the PK-treated bleached samples than in the Mega-L-treated ones. This was because of the more effective endoglucanase (EG) activity as in the case of acid cellulases compared to the cellobiohydrolase $(\mathrm{CBH})$-rich cellulases like neutral cellulases in the formulation of the whole enzyme (Saravanan et al. 2009). EG activity leads to higher level of strength loss which could be expected from a classical endwise cleavage of the cellulose chains in the fibers. EG1 among at least six multiple EGs (Dixit and Jahan 2012) is a faster enzyme than $\mathrm{CBH} 1$ in the initial stages of hydrolysis, but after the cleavage of the more accessible cellulose chains on the surface of the cotton fibers, their action seems to end. In other words, EG effectively opens up more of the fiber structure to attach by $\mathrm{CBH}$ and $\beta$-glucanase. These two components in turn produce water-soluble fragments from the exposed area, and such synergistic action allows for rapid reduction in fiber strength.

\section{Pilling rating}

Pilling ratings of acid- and neutral-stable enzyme-treated fabrics are shown in Table 3.

The pilling resistance ratings of bleached fabric were found to be 4, 3-4, and 3 under 125, 500, and 2000 cycles of operations, respectively, in the pilling test.

Due to biopolishing using the Mega PK enzyme, the rating was improved to 4-5 for sample no. 1 and to 5 in all other 26 samples treated under different parameters for 125 cycles of operation. No change occurred in the specimen surface for samples 2 to 27 under 125 cycles of operation in the pilling test. Under 500 cycles of operation, sample no. 1 showed a rating of 4 ; sample nos. 2 to 7 and 9, 10, and 12 showed a rating of 4-5; and the other 17 samples (sample nos. 8, 11, and 13 to 27) showed a rating of 5 . Again, under 2000 cycles of operation over the PK-treated biopolished samples, sample no. 1 showed a rating of 3-4, another 8 samples (sample nos. 2, 3, 4, 6, 7, 9, 10, 12) showed a rating of 4 , 2 samples (sample nos. 5,8 ) showed a rating of $4-5$, and the other 16 samples (sample nos. 11, 13 to 27) showed no change in pilling testing (rating of 5).

So, the PK-treated samples numbering from 13 to 17 and sample no. 11 showed the best pilling performance. This pilling performance clearly indicated that the acid enzyme significantly improved the pilling resistance of the treated fabric samples. In fact, PK cellulase showed more activity at 1 and $1.5 \%$ than using $0.5 \%$. Due to high biopolishing effect, all surface hairy fibers were removed properly. Therefore, when friction was applied on the treated fabric during the pilling test, the tendency of pill formation was significantly lower and majority caused a rating of 5, i.e., no change at the surface. A good depilling effect was also found due to mechanical agitation which accelerated the cellulase action.

On the other hand, when Mega L was used, the rating was also improved significantly from the bleached fabric. In the case of 125 cycles of operation, only sample nos. 1 and 2 showed a rating of 4-5 while the other 25 samples showed a rating of 5 as compared to a rating of 4 of the bleached sample under the same no. of cycles. In addition, under 500 cycles of operation, 8 samples showed a rating of 4 (sample nos. $1-4,6-7,9,10$ ). The remaining 21 samples showed a rating of 4-5 as compared to a rating of 3-4 of the bleached sample at 500 cycles of operation. Only sample no. 14, i.e., when a $1 \%$ Mega-L-treated biopolished sample was applied at $55{ }^{\circ} \mathrm{C}$ for $50 \mathrm{~min}$, showed a rating of 5 . Under 2000 cycles of operation, sample nos. 1 and 2 showed a rating of 3-4, indicating slight to moderate surface fuzziness, while 8 samples (sample nos. 3, 4, 6, 7, 9-12) showed a rating of 4 and the remaining 17 samples showed a rating of 4-5. Rating improved in all 
Table 3 Pilling ratings of Mega-PK- and Mega-L-treated cotton samples

\begin{tabular}{|c|c|c|c|c|c|c|c|c|c|}
\hline \multirow{3}{*}{$\begin{array}{l}\text { Sample } \\
\text { no. }\end{array}$} & \multirow{3}{*}{$\begin{array}{l}\text { Concentration } \\
(\%)\end{array}$} & \multirow{3}{*}{$\begin{array}{l}\text { Temperature } \\
\left({ }^{\circ} \mathrm{C}\right)\end{array}$} & \multirow{3}{*}{$\begin{array}{l}\text { Time } \\
\text { (min) }\end{array}$} & \multicolumn{6}{|c|}{ Pilling ratings } \\
\hline & & & & \multicolumn{3}{|l|}{ Mega PK } & \multicolumn{3}{|l|}{ Mega L } \\
\hline & & & & 125 cycles & 500 cycles & 2000 cycles & 125 cycles & 500 cycles & 2000 cycles \\
\hline Bleached & - & & & 4 & $3-4$ & 3 & 4 & $3-4$ & 3 \\
\hline 1 & 0.5 & 45 & 40 & $4-5$ & 4 & $3-4$ & $4-5$ & 4 & $3-4$ \\
\hline 2 & 0.5 & 55 & 40 & 5 & $4-5$ & 4 & $4-5$ & 4 & $3-4$ \\
\hline 3 & 0.5 & 65 & 40 & 5 & $4-5$ & 4 & 5 & 4 & 4 \\
\hline 4 & 0.5 & 45 & 50 & 5 & $4-5$ & 4 & 5 & 4 & 4 \\
\hline 5 & 0.5 & 55 & 50 & 5 & $4-5$ & $4-5$ & 5 & $4-5$ & $4-5$ \\
\hline 6 & 0.5 & 65 & 50 & 5 & $4-5$ & 4 & 5 & 4 & 4 \\
\hline 7 & 0.5 & 45 & 60 & 5 & $4-5$ & 4 & 5 & 4 & 4 \\
\hline 8 & 0.5 & 55 & 60 & 5 & 5 & $4-5$ & 5 & $4-5$ & $4-5$ \\
\hline 9 & 0.5 & 65 & 60 & 5 & $4-5$ & 4 & 5 & 4 & 4 \\
\hline 10 & 1 & 45 & 40 & 5 & $4-5$ & 4 & 5 & 4 & 4 \\
\hline 11 & 1 & 55 & 40 & 5 & 5 & 5 & 5 & $4-5$ & 4 \\
\hline 12 & 1 & 65 & 40 & 5 & $4-5$ & 4 & 5 & $4-5$ & 4 \\
\hline 13 & 1 & 45 & 50 & 5 & 5 & 5 & 5 & $4-5$ & $4-5$ \\
\hline 14 & 1 & 55 & 50 & 5 & 5 & 5 & 5 & 5 & $4-5$ \\
\hline 15 & 1 & 65 & 50 & 5 & 5 & 5 & 5 & $4-5$ & $4-5$ \\
\hline 16 & 1 & 45 & 60 & 5 & 5 & 5 & 5 & $4-5$ & $4-5$ \\
\hline 17 & 1 & 55 & 60 & 5 & 5 & 5 & 5 & $4-5$ & $4-5$ \\
\hline 18 & 1 & 65 & 60 & 5 & 5 & 5 & 5 & $4-5$ & $4-5$ \\
\hline 19 & 1.5 & 45 & 40 & 5 & 5 & 5 & 5 & $4-5$ & $4-5$ \\
\hline 20 & 1.5 & 55 & 40 & 5 & 5 & 5 & 5 & $4-5$ & $4-5$ \\
\hline 21 & 1.5 & 65 & 40 & 5 & 5 & 5 & 5 & $4-5$ & $4-5$ \\
\hline 22 & 1.5 & 45 & 50 & 5 & 5 & 5 & 5 & $4-5$ & $4-5$ \\
\hline 23 & 1.5 & 55 & 50 & 5 & 5 & 5 & 5 & $4-5$ & $4-5$ \\
\hline 24 & 1.5 & 65 & 50 & 5 & 5 & 5 & 5 & $4-5$ & $4-5$ \\
\hline 25 & 1.5 & 45 & 60 & 5 & 5 & 5 & 5 & $4-5$ & $4-5$ \\
\hline 26 & 1.5 & 55 & 60 & 5 & 5 & 5 & 5 & $4-5$ & $4-5$ \\
\hline 27 & 1.5 & 65 & 60 & 5 & 5 & 5 & 5 & $4-5$ & $4-5$ \\
\hline
\end{tabular}

the cases with the increase of concentration of cellulase as under 2000 cycles of pilling operation, rating was found to be 3 for the bleached sample.

Neutral cellulases originate from the fungi $H$. insolens and these are less reactive than the acid based cellulase. As Mega L cellulase was applied at $\mathrm{pH} \mathrm{6-7,} \mathrm{this}$ required a longer treatment time to give the similar effect achieved through acid cellulases. EG and EG-rich cellulases as in the case of acid cellulases exhibit better pilling rating at lower weight losses compared to other components of cellulases. The improvements of pilling ratings with the increase of weight loss of the biopolished samples are shown in Fig. 1.

Though depilling action was significantly better in the case of Mega-L-treated samples compared to untreated bleached samples, the action was slightly lower in the case of neutral-stable cellulase-treated samples in comparison to acid-stable cellulase-treated samples, specially under 500 and 2000 cycles of operation. This is due to the more cellulase activity of the acid-stable Mega PK enzyme.

\section{Abrasion resistance (mass loss)}

The results of mass loss due to abrasion testing for Mega-PK- and Mega-L-treated biopolished fabrics are shown in Table 4.

From Table 4, it was obvious that mass loss increased with the increase of number of cycles during abrasion. Again, it was noticed that the amount of mass loss was decreased with the increase of concentration of PK 


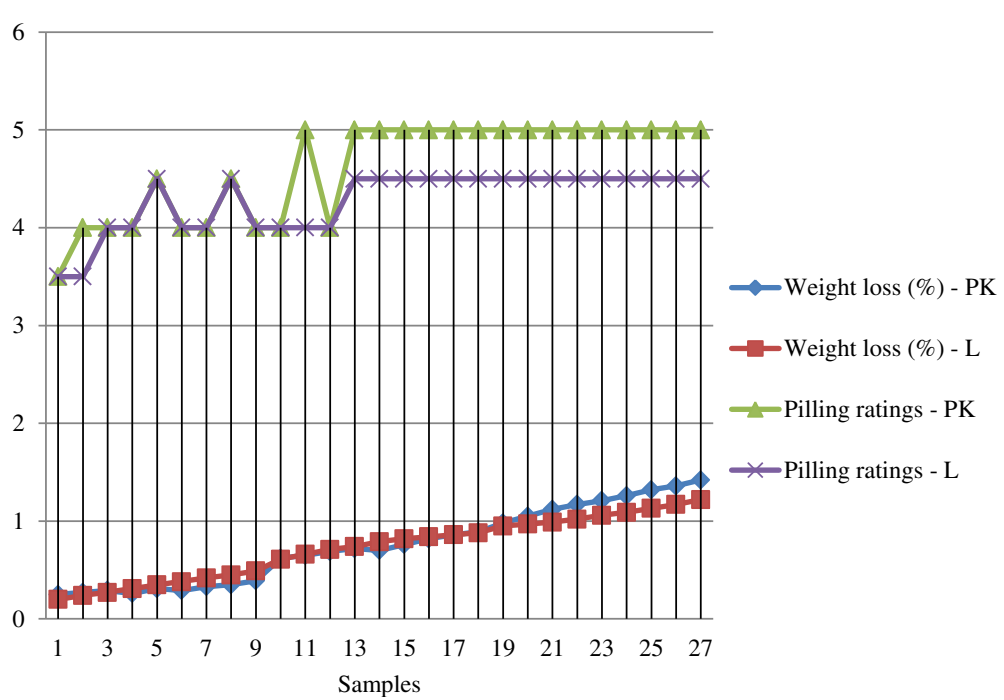

Fig. 1 Weight loss\% vs pilling ratings of biopolished fabrics
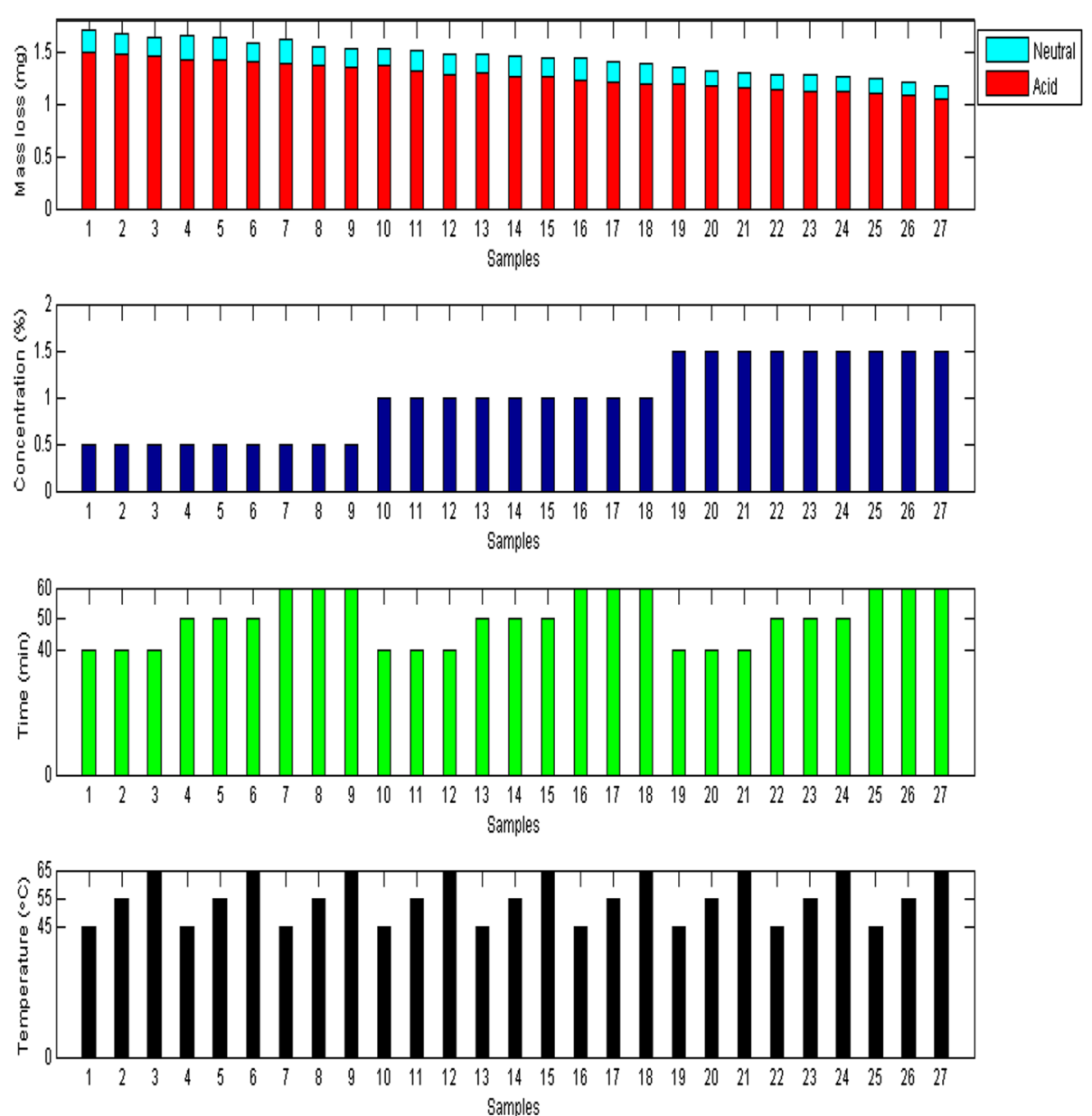

Fig. 2 Mass loss (abrasion) between PK- and L-treated fabrics (1000 cycles) 
Table 4 Abrasion resistance (mass loss) of biopolished cotton fabrics

\begin{tabular}{|c|c|c|c|c|c|c|c|c|c|c|c|c|c|}
\hline \multirow{2}{*}{$\begin{array}{l}\text { Sample } \\
\text { no. }\end{array}$} & \multirow{2}{*}{$\begin{array}{l}\text { Concentration } \\
(\%)\end{array}$} & \multirow{2}{*}{$\begin{array}{l}\text { Temperature } \\
\left({ }^{\circ} \mathrm{C}\right)\end{array}$} & \multirow{2}{*}{$\begin{array}{l}\text { Time } \\
(\mathrm{min})\end{array}$} & \multicolumn{5}{|c|}{ Mass loss (mg) for Mega PK } & \multicolumn{5}{|c|}{ Mass loss (mg) for Mega L } \\
\hline & & & & 100 cycles & 250 cycles & 500 cycles & 750 cycles & 1000 cycles & 100 cycles & 250 cycles & 500 cycles & 750 cycles & 1000 cycles \\
\hline Bleached & - & & & 0.88 & 1.32 & 1.59 & 1.68 & 1.90 & 0.88 & 1.32 & 1.59 & 1.68 & 1.32 \\
\hline 1 & 0.5 & 45 & 40 & 0.40 & 0.90 & 1.06 & 1.20 & 1.50 & 0.60 & 1.10 & 1.42 & 1.53 & 1.72 \\
\hline 2 & 0.5 & 55 & 40 & 0.38 & 0.89 & 1.04 & 1.19 & 1.48 & 0.58 & 1.08 & 1.38 & 1.51 & 1.69 \\
\hline 3 & 0.5 & 65 & 40 & 0.37 & 0.88 & 1.03 & 1.18 & 1.46 & 0.57 & 1.09 & 1.35 & 1.49 & 1.65 \\
\hline 4 & 0.5 & 45 & 50 & 0.35 & 0.85 & 1.01 & 1.17 & 1.43 & 0.55 & 1.07 & 1.30 & 1.48 & 1.67 \\
\hline 5 & 0.5 & 55 & 50 & 0.33 & 0.82 & 0.99 & 1.16 & 1.43 & 0.52 & 1.05 & 1.28 & 1.48 & 1.64 \\
\hline 6 & 0.5 & 65 & 50 & 0.30 & 0.80 & 0.98 & 1.15 & 1.42 & 0.50 & 1.04 & 1.25 & 1.47 & 1.60 \\
\hline 7 & 0.5 & 45 & 60 & 0.32 & 0.76 & 0.96 & 1.15 & 1.40 & 0.48 & 1.02 & 1.22 & 1.45 & 1.62 \\
\hline 8 & 0.5 & 55 & 60 & 0.28 & 0.72 & 0.95 & 1.14 & 1.38 & 0.46 & 1.01 & 1.19 & 1.42 & 1.55 \\
\hline 9 & 0.5 & 65 & 60 & 0.25 & 0.70 & 0.94 & 1.12 & 1.35 & 0.44 & 0.99 & 1.18 & 1.40 & 1.53 \\
\hline 10 & 1 & 45 & 40 & 0.21 & 0.67 & 0.92 & 1.10 & 1.37 & 0.41 & 0.97 & 1.19 & 1.37 & 1.53 \\
\hline 11 & 1 & 55 & 40 & 0.18 & 0.66 & 0.90 & 1.09 & 1.32 & 0.40 & 0.96 & 1.20 & 1.38 & 1.52 \\
\hline 12 & 1 & 65 & 40 & 0.15 & 0.65 & 0.89 & 1.08 & 1.28 & 0.40 & 0.95 & 1.17 & 1.36 & 1.48 \\
\hline 13 & 1 & 45 & 50 & 0.12 & 0.62 & 0.87 & 1.10 & 1.30 & 0.37 & 0.93 & 1.15 & 1.35 & 1.48 \\
\hline 14 & 1 & 55 & 50 & 0.14 & 0.60 & 0.86 & 1.09 & 1.27 & 0.35 & 0.91 & 1.16 & 1.33 & 1.47 \\
\hline 15 & 1 & 65 & 50 & 0.10 & 0.61 & 0.85 & 1.08 & 1.26 & 0.32 & 0.90 & 1.18 & 1.32 & 1.45 \\
\hline 16 & 1 & 45 & 60 & 0.08 & 0.61 & 0.84 & 1.07 & 1.24 & 0.30 & 0.87 & 1.14 & 1.30 & 1.45 \\
\hline 17 & 1 & 55 & 60 & 0.07 & 0.58 & 0.83 & 1.06 & 1.21 & 0.28 & 0.86 & 1.13 & 1.29 & 1.42 \\
\hline 18 & 1 & 65 & 60 & 0.06 & 0.55 & 0.81 & 1.05 & 1.20 & 0.25 & 0.84 & 1.10 & 1.27 & 1.40 \\
\hline 19 & 1.5 & 45 & 40 & 0.08 & 0.52 & 0.80 & 1.04 & 1.20 & 0.24 & 0.80 & 1.08 & 1.28 & 1.36 \\
\hline 20 & 1.5 & 55 & 40 & 0.07 & 0.50 & 0.80 & 1.04 & 1.18 & 0.23 & 0.78 & 1.09 & 1.26 & 1.32 \\
\hline 21 & 1.5 & 65 & 40 & 0.06 & 0.48 & 0.79 & 1.02 & 1.16 & 0.22 & 0.76 & 1.07 & 1.24 & 1.30 \\
\hline 22 & 1.5 & 45 & 50 & 0.05 & 0.47 & 0.78 & 1.01 & 1.14 & 0.20 & 0.74 & 1.05 & 1.22 & 1.29 \\
\hline 23 & 1.5 & 55 & 50 & 0.04 & 0.46 & 0.77 & 1.02 & 1.13 & 0.19 & 0.72 & 1.02 & 1.21 & 1.28 \\
\hline 24 & 1.5 & 65 & 50 & 0.04 & 0.45 & 0.76 & 0.99 & 1.12 & 0.18 & 0.70 & 1.01 & 1.20 & 1.27 \\
\hline 25 & 1.5 & 45 & 60 & 0.04 & 0.44 & 0.78 & 0.98 & 1.10 & 0.17 & 0.66 & 0.97 & 1.22 & 1.25 \\
\hline 26 & 1.5 & 55 & 60 & 0.03 & 0.42 & 0.76 & 0.97 & 1.08 & 0.15 & 0.64 & 0.95 & 1.20 & 1.22 \\
\hline 27 & 1.5 & 65 & 60 & 0.02 & 0.41 & 0.74 & 0.96 & 1.06 & 0.12 & 0.62 & 0.92 & 1.19 & 1.18 \\
\hline
\end{tabular}


cellulase. As for example, under 1000 cycles of abrasion testing, the mass loss of the bleached sample was found to be $1.90 \mathrm{mg}$ while the maximum mass loss was found to be $1.50 \mathrm{mg}$ in sample no. 1, and this gradually reduced to a minimum mass loss of $1.06 \mathrm{mg}$ with the increase of concentration, time, and temperature. Only in cases of sample nos. 4 and 5 mass loss was found to be equal, i.e., $1.43 \mathrm{mg}$.

Again, under other cycles such as 100, 250, 500, and 750 cycles, mass loss was found decreased with the increase of concentration, time, and temperature with some exceptions. For 100, 250, 500, and 750 cycles, in the case of sample no. 1, maximum mass losses were found to be $0.40,0.90,1.06$, and $1.20 \mathrm{mg}$, respectively, and minimum losses were found to be $0.02,0.41,0.74$, and $0.96 \mathrm{mg}$, respectively, in the case of sample no. 27 (PK $1.5 \%$, treatment temperature $65^{\circ} \mathrm{C}$, time $60 \mathrm{~min}$ ).

Due to superficial treatment of cellulase on cellulosic fibrils and microfibrils, protruding hairy fibers are removed, as a result of which the surface of the fabric became cleaner. For this reason, resistance to abrasion was better in the case of the cellulase-treated samples than the untreated bleached sample. Again, biopolishing effect was higher in the use of a higher concentration (1.5 \%) of PK cellulase; correspondingly, resistance to abrasion was better and hence mass loss was found lower.

In the case of the neutral cellulase enzyme, using $0.5 \%$ concentration under 1000 cycles during abrasion testing, the maximum mass loss found in the case of sample no. 1 was $1.72 \mathrm{mg}$, and it decreased gradually with the increase of concentration, time, and temperature, and finally minimum loss was found to be $1.18 \mathrm{mg}$ in sample no. 27 . No exception was found in such trend at 1000 cycles of abrasion testing. However, except in a few cases, a similar trend was noticeable under 100-, 250-, 500-, and 750cycle testings.

It is known that abrasion is the physical destruction of fibers resulting from frictional forces developed by mechanical repetition of lateral stresses. This causes rupture of fibers from their normal position through bending and flexing. In both acid- and neutral-stable cellulase-treated samples, a very little amount of mass loss occurred due to the smoothness of the fabric surface after biopolishing action, causing higher abrasion resistance performance.

Figure 2 shows a comparison of mass loss due to abrasion of Mega-PK- and Mega-L-treated bleached cotton samples. In Fig. 2, in all cases, the mass loss values were lower in the PK-treated samples; thus, it can be said that slightly better resistance to abrasion was found in the acid-stable cellulase-treated samples. Neutral-stable cellulases were less reactive causing less degradation to cellulose; as a consequence of which, weight loss as well as strength loss was found lower in this study. Hence, mass loss was found slightly higher during abrasion testing in the Mega-Ltreated cotton samples, which showed lower resistance to abrasion.

\section{Bending length}

The bending length of the acid- and neutral-stable enzyme-treated samples is shown in Table 5.

The average bending length of the bleached fabric was found to be $1.48 \mathrm{~cm}$ in a wale direction. For Mega PK enzyme application, in 24 cases, the bending length of biopolished fabrics was found decreased than that of the bleached fabric in the wale direction. Only three samples (sample nos. 18, 22, and 25) showed a slight increase in the bending lengths which were 1.58, 1.53,

Table 5 Bending length of biopolished cotton fabrics (wale direction)

\begin{tabular}{|c|c|c|}
\hline \multirow[t]{2}{*}{ Sample no. } & \multicolumn{2}{|c|}{ Average bending length $(\mathrm{cm})$} \\
\hline & Mega PK & Mega L \\
\hline Bleached sample & 1.48 & 1.48 \\
\hline 1 & 1.23 & 1.4 \\
\hline 2 & 1.23 & 1.45 \\
\hline 3 & 1.1 & 0.98 \\
\hline 4 & 1.2 & 1.25 \\
\hline 5 & 1.4 & 1.63 \\
\hline 6 & 1.1 & 1.5 \\
\hline 7 & 1.2 & 1.33 \\
\hline 8 & 1.1 & 1.18 \\
\hline 9 & 1.1 & 1.03 \\
\hline 10 & 1.1 & 1.08 \\
\hline 11 & 1.1 & 0.85 \\
\hline 12 & 1.35 & 0.93 \\
\hline 13 & 1.32 & 1.3 \\
\hline 14 & 1.42 & 0.98 \\
\hline 15 & 1.24 & 1.46 \\
\hline 16 & 1.3 & 1.05 \\
\hline 17 & 1.36 & 0.9 \\
\hline 18 & 1.58 & 1.2 \\
\hline 19 & 1.4 & 1.11 \\
\hline 20 & 1.28 & 1.25 \\
\hline 21 & 1.35 & 1.13 \\
\hline 22 & 1.53 & 1.2 \\
\hline 23 & 1.01 & 0.83 \\
\hline 24 & 1.33 & 1.53 \\
\hline 25 & 1.61 & 1.15 \\
\hline 26 & 1.35 & 1.45 \\
\hline 27 & 1.18 & 1.55 \\
\hline
\end{tabular}


and $1.61 \mathrm{~cm}$, respectively. The lowest average bending length was found to be $1.01 \mathrm{~cm}$ in the case of sample no. 23 which was $31.62 \%$ lower than that of the bleached sample.

In the application of the Mega L enzyme, the average bending length of the biopolished fabrics was decreased than that of the bleached fabric in 24 cases; only in three samples, sample nos. 5, 24, and 27, the bending lengths were $1.63,1.53$, and $1.55 \mathrm{~cm}$, respectively, in the wale direction. The bending length was found lowest $0.83 \mathrm{~cm}$ $(44.26 \%)$ in sample no. 23. Biopolishing leads to a cleaning and depilling effect due to complete cellulase action. That is why softness was improved considerably as a result of decreased bending length.

\section{Conclusions}

In this study, the biopolishing effect on cotton knit fabric was investigated using two types of cellulases concerning the working parameters (enzyme concentration, treatment time, and temperature). In the case of Mega PK and Mega L, with the increase of concentration, time, and temperature, weight loss was increased in all cases, except in two treatments of PK cellulase. Fabric weight loss was found within $0.25-0.39 \%$ using $0.5 \%$ PK, 0.62-0.89 \% using $1 \%$ PK, and 0.98-1.42 \% using $1.5 \%$ PK. Again, it was found to be within $0.2-0.49 \%$ using $0.5 \% \mathrm{~L}, 0.61-0.88 \%$ using $1 \% \mathrm{~L}$, and $0.95-1.22 \%$ using $1.5 \% \mathrm{~L}$ cellulase. Fabric strength loss was found to be within 1.7 to $7.4 \%$ using $0.5 \%$ PK, 8.2 to $15.6 \%$ using $1 \% \mathrm{PK}$, and 16.5 to $24.7 \%$ using $1.5 \%$ PK. Again, strength loss ranged 1.5 to $5.9 \%, 6.6$ to $12.4 \%$, and 12.5 to $18.9 \%$ using $0.5,1$, and $1.5 \%$ Mega L, respectively. On the other hand, pilling resistance was improved when the fabric was treated with cellulases in all cases. Abrasion resistance was improved due to biopolishing and acidic cellulase treatment showed better resistance than the neutral treatment. With the increase of concentration, time, and temperature, mass loss decreased except in a few cases. The bending length of biopolished fabrics was found lower in most cases than that of the bleached fabric. Average bending length decreased maximum $31.62 \%$ using Mega PK and $44.26 \%$ using Mega L. The reduction of bending length ensured the better softness of the biopolished fabrics. Finally, on the basis of the observed results, it can be suggested that Mega PK showed a better result when using $1 \%$ concentration at $55{ }^{\circ} \mathrm{C}$ for $40 \mathrm{~min}$. On the other hand, a comparatively better result was found using $1 \%$ Mega $\mathrm{L}$ at $55^{\circ} \mathrm{C}$ for $50 \mathrm{~min}$.

\section{Competing interests}

The author declares that he has no competing interests.

\section{References}

Andreaus, J, Olekszyszen, DN, \& Silveria, MHL. (2014). Processing of cellulosic textile materials with cellulases. In JD Fontaza, M Tiboni, \& A Grzybowski (Eds.), Cellulose and other naturally occurring polymers (pp. 11-19). ISBN 978-81-308-0543-6.

Azevedo, H, Bishop, D, \& Cavaco-Paulo, A. (2000). Effects of agitation level on the adsorption, desorption, and activities on cotton fabric of full length and 63 core domains of EGV (Humicola insolens) and CenA (Cellulomonas fimi). Enzyme and Microbial Technology, 27;325-329.

Choudhury, AKR. (2006). Textile preparation and dyeing (pp. 149-150). New Delhi, India: Oxford and IBH Publishing Ltd.

Dixit, S, \& Jahan, S. (2012). Optimization of the pre-treatment process with acid cellulase enzyme to improve physical properties of handloom cotton fabric. International Journal of Home Economics, 5(2), 130-139.

Doshi, R, \& Shelke, V. (2001). Enzymes in textile industry - an environmentfriendly approach. Indian Journal of Fiber \& Textile Research, 26, 202-205.

El-Sayed, H, El-Gabry, L, \& Kantouch, F. (2010). Effect of biocarbonization of coarse wool on its dyeability. Indian Journal of Fiber \& Textile Research, 35(4), 330-336.

Hebeish, A, Kamel, MM, \& Helmy HM El Hawary, NS. (2013). Science-based options for application of cellulase biotreatment and reactive dyeing to cotton fabrics. Life Science Journal, 10(4, 6), 3281-3289.

Heikinheimo, L, Buchert, J, \& Miettinen-Oinonen, A. (2000). Treating denim fabrics with Trichoderma reesei cellulases. Textile Research Journal, 70(11), 969-973.

Mojsov, K. (2014a). Biopolishing enzymes and their applications in textiles: a review. Tekstilna industrija, 61(2), 20-24.

Mojsov, K. (2014b). Trends in bio-processing of textiles: a review. Advanced technologies, 3(2), 135-138.

Morgado, J, Cavaco-Paulo, A, \& Marie-Alice, R. (2000). Enzymatic treatment of lyocell_clarification of depilling mechanisms. Textile Research Journal., 70(8), 696-699.

Rau, M, Heidemann, C, Pascoalin, AM, Filho, EXF, Camassola, M, Dillon, PC, Chagas, FD, \& Andreaus, J. (2008). Application of cellulases from Acrophial ophoranainiana and Penicillium echinulatum in textile processing of cellulosic fibers. Biocatalysts and Biotransformation., 26(5), 383-390.

Saravanan, D, Vasanthi, NS, \& Ramachandran, T. (2009). A review on influential behavior of biopolishing on dyeability and certain physicomechanical properties of cotton fabrics. Carbohydrate Polymers, 76, 1-7.

Schimper, C, Keckeis, R, Ibanescu, C, Burtscher, E, Manian, AP, \& Bechtold, T. (2004). Influence of steam and dry heat pretreatment on fiber properties and cellulase degradation of cellulosic fibers. Biocatalysts and Biotransformation., 22(5-6), 383-389.

Schimper, CB, Ibanescu, C, \& Bechtold, T. (2009). Effect of alkali pre-treatment on hydrolysis of regenerated cellulose fibers (part 1: viscose) by cellulases. Cellulose., 16(6), 1057-1068.

Schindler, WD, \& Hauser, PJ. (2004). Chemical finishing of textiles. In Finishing with enzymes: bio-finishes for cellulose (pp. 181-188). Cambridge, England: Woodhead Publishing Ltd.

Shah, SR. (2014). Chemistry and applications of cellulase in textile wet processing. Research Journal of Engineering Sciences, 3(2), 1-5.

Steward, MA. (2005). Biopolishing cellulosic nonwovens. North Carolina State University: PhD Thesis.

Ulson de Souza, AA, Ferreira, FCP, Souza, GU, \& SMA. (2013). Influence of pretreatment of cotton yarns prior to biopolishing. Carbohydrate Polymers, 93, 412-415.

\section{Submit your manuscript to a SpringerOpen ${ }^{\circ}$ journal and benefit from:}

- Convenient online submission

Rigorous peer review

- Immediate publication on acceptance

- Open access: articles freely available online

- High visibility within the field

- Retaining the copyright to your article

Submit your next manuscript at springeropen.com

Submit your next manuscript at springeropen.com

